\title{
Photocatalytic performance of Ag-modified natural zeolite catalyst for photocatalysis degradation of Methylene Blue (MB) under VIS irradiation
}

\author{
L. A. Colar ${ }^{1}$, A. Jakab ${ }^{1}$, F. Manea ${ }^{1}$, R. Pode ${ }^{1} \&$ C. Orha ${ }^{2}$ \\ ${ }^{1}$ Faculty of Industrial Chemistry and Environmental Engineering, \\ "Politehnica" University of Timisoara, Romania \\ ${ }^{2}$ Department of Condensed Matter, National Institute of Research- \\ Development for Electrochemistry and Matter, Timisoara, Romania
}

\begin{abstract}
In this study, Ag-modified natural zeolite catalyst ( $\left.\mathrm{Z}-\mathrm{Ag}_{\mathrm{red}}\right)$ was synthesized by chemical activation prior to the ion exchange and followed by a silver reduction with sodium boron hydride. The surface characterization of $\mathrm{Z}-\mathrm{Ag}_{\mathrm{red}}$ has been investigated by X-ray diffraction, FT-IR spectroscopy, SEM microscopy and EDX analysis. Also, UV-VIS diffuse reflectance (DRUV-VIS) spectroscopy was used to determine the light absorption properties of the catalyst. The effect of silver reduction was noticed by comparison with the characterization of silvermodified natural zeolite by ion-exchange without the reduction stage. The photocatalytic performance of $\mathrm{Z}-\mathrm{Ag}_{\text {red }}$ catalyst was proved by photocatalysis application for the decolorisation and degradation of Methylene Blue (MB) dye containing wastewater under visible irradiation. The optimum operating parameters were determined based on the assessment of the photocatalytic process efficiency as a function of the catalyst dose, the initial $\mathrm{pH}$, and the initial concentration of dye. The good results regarding the photocatalytic degradation of $\mathrm{MB}$ dye using $\mathrm{Z}-\mathrm{Ag}_{\mathrm{red}}$ catalyst claim it as a potential for the real photocatalysis application in MB-containing wastewater under solar light.

Keywords: Ag-modified natural zeolite catalyst, photocatalysis, VIS irradiation, MB dye.
\end{abstract}




\section{Introduction}

Dyes are widely used as coloring agents in a variety of industries, such as textiles, cosmetics, pulp mills, printing, foods, and plastics. Because many organic dyestuffs are harmful to human beings and hazardous to aquatic organisms, removal of dyestuffs from wastewater has received considerable attention over the past decades.

In order to handle the dye removal from water, various methods have been investigated. Among biodegradation, methods like coagulation [1], adsorption [2] and advanced oxidation processes (AOPs) [3, 4] have been employed. All these processes exhibit some specific advantages or drawbacks.

Among AOPs, heterogeneous photocatalysis is considered to be one of the most emerging oxidation technology due to the lack of limitations in mass transfer, the ability to be carried out under ambient conditions (atmospheric oxygen is used as oxidant), and may lead to complete mineralization of organic carbon to $\mathrm{CO}_{2}$.

The incorporation of transition metals with different oxidation states into zeolites has been studied to develop materials with potential applications in many fields, as catalysis and water treatment $[5,6]$.

The aim of this work was to evaluate the photocatalytic performance of Agmodified natural zeolite for photocatalysis degradation of Methylene Blue (MB) under VIS irradiation. The catalyst was structurally characterized and the photocatalytic activity was determined for MB dye degradation under VIS irradiation.

\section{Materials and methods}

\subsection{Chemicals}

Methylene Blue (MB) (commercial grade) with a molecular weight of $373.9 \mathrm{~g} \cdot \mathrm{mol}^{-1}$ was supplied by Pekin Chemical Works Peking (China).

The chemical used for synthesis, i.e., silver nitrate $\left(\mathrm{AgNO}_{3}\right)$ hydrochloric acid $(\mathrm{HCl})$, sodium chloride $(\mathrm{NaCl})$, sodium boron hydride $\left(\mathrm{NaBH}_{4}\right)$ were purchased from Merck Company. Romanian zeolitic mineral from Mirsid was supplied by CEMACON Company, Romania. The mineral was powdered and sieved with a Multilab sieve shaker. The mass composition of the mineral is: $62.20 \%$, wt. $\mathrm{SiO}_{2}, 11.65 \%$, wt. $\mathrm{Al}_{2} \mathrm{O}_{3}, 1.30 \%$, wt, $\mathrm{Fe}_{2} \mathrm{O}_{3}, 3.74 \%$, wt. $\mathrm{CaO}, 0.67 \%$, wt. $\mathrm{MgO}$, $3.30 \%$, wt. $\mathrm{K}_{2} \mathrm{O}, 0.72 \%$, wt. $\mathrm{Na}_{2} \mathrm{O}, 0.28 \%$, wt. $\mathrm{TiO}_{2}$.

\subsection{Preparation of Ag-modified natural zeolite ( $\left.\mathrm{Z}-\mathrm{Ag}_{\text {red }}\right)$ catalyst}

Ag-modified natural zeolite $\left(\mathrm{Z}-\mathrm{Ag}_{\mathrm{red}}\right)$ catalyst was synthesized by a chemical activation prior to the ion exchange and followed by a silver reduction with sodium boron hydride. The preparation of the chemically modified zeolite presumes two stages to reach acid form ( $\mathrm{H}$ form) by using $1 \mathrm{M} \mathrm{HCl}$ solution and sodium form ( $\mathrm{Na}$ form) with $1 \mathrm{M} \mathrm{NaCl}$ solution for a more efficient ion exchange. 
For preparation of $\mathrm{Ag}^{+}$-modified zeolite (Z-Ag), $\mathrm{Na}$ form of zeolite was added to a volume of $0.03 \mathrm{M} \mathrm{Ag}^{+}$solution (as nitrate salt) corresponding to a solid/liquid ratio of $1 / 100$. The ion exchange process has been conducted under magnetic stirring, at room temperature, for $8 \mathrm{~h}$. The Z-Ag material was filtered off, washed with water and dried at $100^{\circ} \mathrm{C}$. Z- $\mathrm{Ag}_{\text {red }}$ catalyst was obtained by the reduction process of $\mathrm{Z}-\mathrm{Ag}$ using a $0.04 \mathrm{M} \mathrm{NaBH}_{4}$ solution $(\mathrm{pH}=12)$, at 1/4 molar ratio of $\mathrm{Ag} / \mathrm{NaBH}_{4}$. The $\mathrm{Z}-\mathrm{Ag}_{\text {red }}$ catalyst was separated by centrifugation and subjected to the repeated washing-centrifugation, until disappearance of residual alkalinity.

\subsection{Characterization of the photocatalyst}

The crystallinity of the prepared samples was measured by X-ray diffraction (XRD) using PANalytical X'PertPRO MPD Diffractometer with a Cu tube.

The light absorption properties of the materials were studied by UV-VIS diffuse reflectance spectroscopy (DRUV-VIS), performed under ambient conditions using Lambda 950 Perkin Elmer in the wavelength range of 200 $600 \mathrm{~nm}$. The bond vibration of the catalyst was analyzed by Fourier transform infrared spectrometry (FT-IR) using a JASCO FT/IR-430 spectrometer. The surface morphology was studied by a scanning electron microscopy coupled with the energy dispersive X-ray analysis (SEM/EDX), using Inspect S PANalytical model detector.

\subsection{Photocatalytic experiments}

All experiments regarding adsorption and photocatalysis processes were carried out under magnetic stirring at $20^{\circ} \mathrm{C}$ into a RS-1 photo-catalytic reactor (Heraeus, Germany), which consists of a submerged lamp surrounded by a quartz shield. Solutions of $\mathrm{MB}$ dye at different concentrations (prepared from an initial stock solution of $1 \mathrm{~g} \cdot \mathrm{L}^{-1}$ ) were placed into the photoreactor and irradiated with an UV light set between 280 and $360 \mathrm{~nm}$ when UV photocatalytic process was employed, and with a VIS light set between 460 and $510 \mathrm{~nm}$ in the case of VIS photocatalytic process, for 180 minutes. A system of water recirculation maintained a constant temperature of $20^{\circ} \mathrm{C}$ for the whole period of photocatalytic experiments.

The catalyst was placed into $400 \mathrm{~mL} \mathrm{MB}$ solution. Prior to irradiation, the suspension was stirred continuously in the dark for 30 min to reach the steadystate conditions. The concentration of the dye in the bulk solution at the end point of the adsorption step was considered as the initial concentration value for the investigation of the photocatalytic process. At regular time intervals of irradiation, samples were collected and filtered through a Milipore filter (pore size of $0.45 \mu \mathrm{m}$ ) in order to remove the zeolite from the aqueous solution. The concentration of MB solutions was measured with a Varian Cary 100 UV-VIS spectrophotometer.

The assessment of the photocatalysis performance was carried out as discoloration and degradation efficiencies. The discoloration and degradation efficiencies were determined based on the absorbance recorded at $663 \mathrm{~nm}$ and 
$291 \mathrm{~nm}$, respectively. The $\mathrm{pH}$ of dye solutions was adjusted by adding diluted $\mathrm{H}_{2} \mathrm{SO}_{4}$ and $\mathrm{NaOH}$ solutions (analytical grade), using an Inolab $\mathrm{pH}$-meter.

\section{Results and discussion}

\subsection{Structural and morphological characterization of $\mathbf{Z}-\mathbf{A g}_{\text {red }}$ catalyst}

\subsubsection{XRD analysis}

The XRD pattern of Ag-modified natural zeolite catalyst (Z-Agred) is illustrated in fig. 1. For comparison, the XRD patterns of the natural zeolite in $\mathrm{Na}$ form (fig.1, spectrum (a)) and of the $\mathrm{Ag}^{+}$-modified zeolite (Z-Ag) are also shown (fig. 1, spectrum (b)).

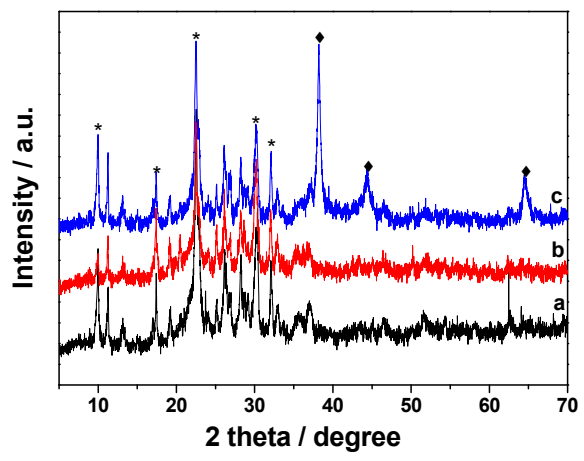

Figure 1: XRD patterns for (a) Z-Na, (b) Z-Ag and (c) Z-Agred ${ }_{\text {* }}$ clinoptilolite; -mettalic silver.

It can be seen that the main peak positions of natural zeolite (clinoptilolite) (2 theta: $9.92^{\circ} ; 22.5^{\circ} ; 25.8^{\circ} ; 30.05^{\circ} ; 32^{\circ}$ ) [7] are found also in the XRD pattern of the natural zeolite in $\mathrm{Na}$ form. The peak corresponding to 2 theta $\sim 26.6^{\circ}$ is attributed to $\mathrm{Na}^{+}$presence within zeolite lattice.

The study of the XRD patterns confirms that no transition of zeolite phases occurred during $\mathrm{Ag}^{+}$ion exchange. Variations in the relative intensities of the clinoptilolite peaks (2 theta: $9.92^{\circ} ; 11.2^{\circ}$ ) were found in the XRD pattern of Z$\mathrm{Ag}$, after $\mathrm{Ag}$ ion exchange. These variations can be associated mainly with differences in the nature, amount and position of the extra-framework species in clinoptilolite channels [8]. The presence of new peaks (2 theta: $38^{\circ} .1 ; 44.3^{\circ}$; $64.5^{\circ}$ ) can be attributed to the presence of metallic $\mathrm{Ag}$, which confirmed the occurrence of reduction process of Ag ions [9].

\subsubsection{DRUV-VIS spectroscopy}

Figure 2 presents the DRUV-VIS spectra of Na form of zeolite (a), Z-Ag after ion exchange process (b) and Ag-modified natural zeolite catalyst $\left(\mathrm{Z}-\mathrm{Ag}_{\mathrm{red}}\right)$ after reduction process (c). 


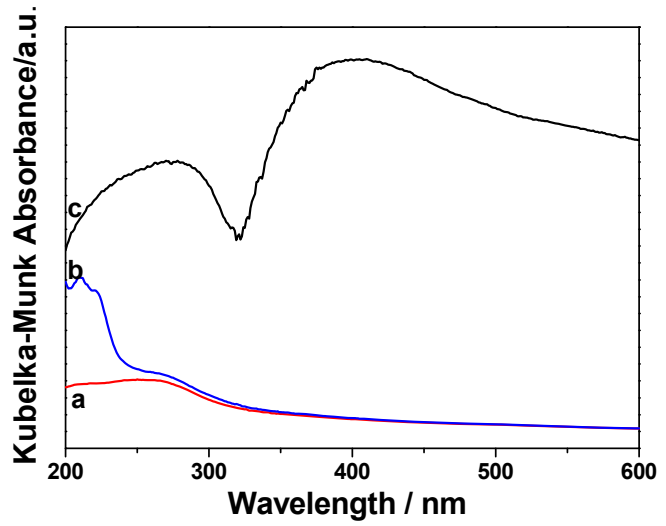

Figure 2: $\quad$ DRUV-VIS spectra of (a) Z-Na, (b) Z -Ag and (c) Z-Agred.

DRUV-VIS patterns are examined to determine the light absorption quantification and absorption wavelength range correlated with band gap energy.

After ion exchange appearance of a new peak at $210 \mathrm{~nm}$, assigned to $\mathrm{Ag}^{+}$ions is observed in the spectra of Z-Ag (fig. 2(b)) [9]. This peak disappeared in the Z$\mathrm{Ag}_{\text {red }}$ spectrum, which exhibits two broad absorption bands (Fig. 2(c)). The first one, with asymmetric peak centered at $276 \mathrm{~nm}$, is attributed to small $\mathrm{Ag}_{4}{ }^{\delta+}$ clusters [8]. The other one, in visible region, with asymmetric peak centered at $400 \mathrm{~nm}$, is assigned to silver particles [9]. The relative intensity of the second band (in visible region) is higher than the relative intensity of the first band, which indicates the higher contribution of silver particles compared with the $\mathrm{Ag}_{4}{ }^{\delta+}$ clusters, a desired aspect regarding the photocatalytic process.

\subsubsection{FT-IR analysis}

The structural information about the $\mathrm{Na}$ form of clinoptilolite (fig. 3(a)) and Z$\mathrm{Ag}_{\text {red }}$ photocatalyst (fig. 3(b)) were obtained by FT-IR spectroscopy.

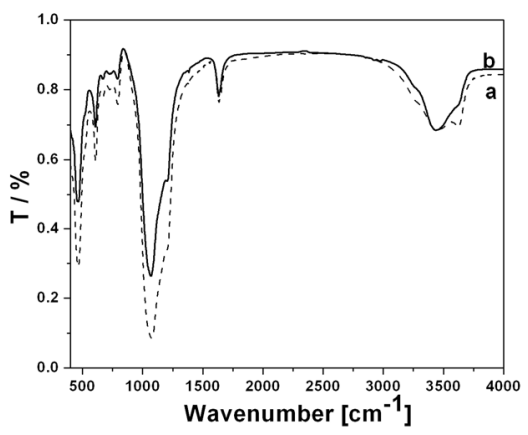

Figure 3: $\quad$ FT-IR spectra of (a) Z-Na and (b) Z-Agred. 
Peaks related to the isolated and H-bonded O-H stretching at 3625 and $3450 \mathrm{~cm}^{-1}$, respectively, were identified in the FT-IR spectra of Z-Na sample (fig.4(a)) [7]. The peak at $3625 \mathrm{~cm}^{-1}$ disappeared in the spectra of Z-Ag red sample (Fig. 3(b)), but a shoulder can be observed at the same wave number. In the spectra of Z-Ag ${ }_{\text {red }}$ sample, the peak centered at $3450 \mathrm{~cm}^{-1}$ characterised by the same intensity but slightly narrowed can be observed.
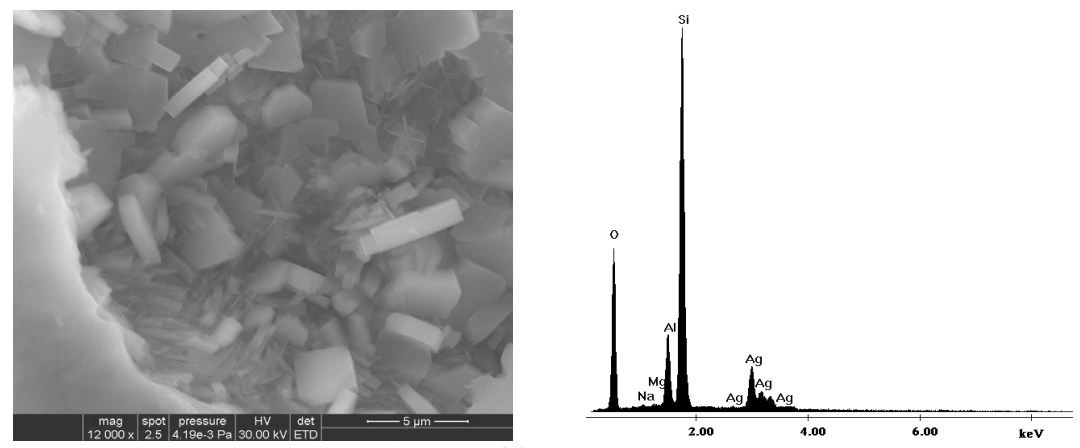

(a)

Figure 4: $\quad$ SEM morphology (a) and EDX spectra (b) for $\mathrm{Z}-\mathrm{Ag}_{\text {red. }}$

The peak at 1630 (Lewis sites) is assigned to the zeolitic water in the channels of the samples [10], which is found in the $\mathrm{Z}-\mathrm{Ag}_{\text {red }}$ spectrum also.The range between 1250 and $430 \mathrm{~cm}^{-1}$ is composed of four bands centered at 463, 609, 790 and $1070 \mathrm{~cm}^{-1}$, with a shoulder at $1200 \mathrm{~cm}^{-1}$, which are characteristic to clinoptilolite and correspond to the symmetric and asymmetric vibration of the $(\mathrm{Al}, \mathrm{Si}) \mathrm{O}$ group [11].

All vibrations bands between 1250 and $430 \mathrm{~cm}^{-1}$ characteristic to clinoptilolite are found in the FT-IR spectrum of $\mathrm{Z}-\mathrm{Ag}_{\text {red }}$ sample. FT-IR spectrum of Z-Agred sample is similar as Z-Na, the intensities of the peaks being slight reduced, especial for the external groups. Based on these results, it can be concluded that the reduced silver particles are located onto the zeolite surface [11].

\subsubsection{Scanning electron microscopy (SEM) and energy dispersive X-ray analysis (EDX) results}

The SEM image and EDX spectra of the Z- $\mathrm{Ag}_{\text {red }}$ photocatalyst is presented in fig. 4.

No changes were observed in the morphology of the Z-Agred sample (Fig. 4(a)) in comparison to $\mathrm{Na}$ form of zeolite [12].

\subsection{VIS photocatalytic degradation}

The photocatalytic performance of $\mathrm{Z}-\mathrm{Ag}_{\text {red }}$ catalyst was studied as a function of $\mathrm{pH}$, catalyst dose and the initial dye concentration under VIS irradiation. 


\subsection{1 pH influence}

The influence of $\mathrm{pH}$ on the degradation and decolorization of $\mathrm{MB}$ dye in aqueous solution was studied in the $\mathrm{pH}$ range of 3 to 11 (Fig. 5(a),(b)).

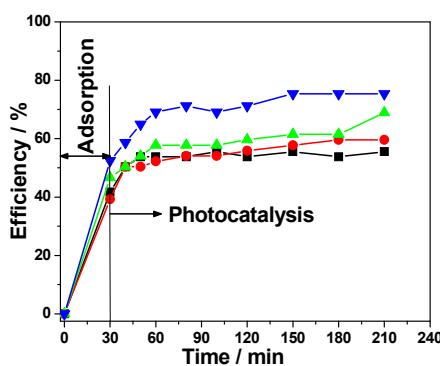

(a)

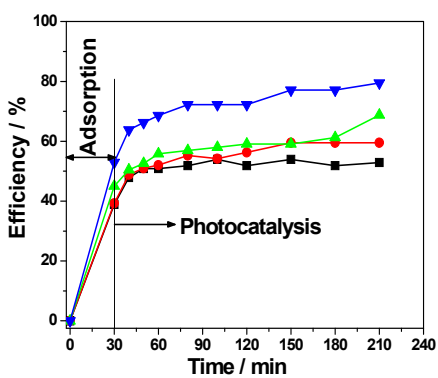

$$
\text { --pH } 3 ; \bullet-\mathrm{pH} 5.4 ; \triangle-\mathrm{pH} 9 ; \boldsymbol{\nabla}-\mathrm{pH} 11
$$

Figure 5: Efficiencies of $\mathrm{MB}$ degradation (a) and discoloration (b) at $\mathrm{pH}$ 3-11, during VIS irradiation. Conditions: $50 \mathrm{mg} \cdot \mathrm{L}^{-1} \mathrm{MB}$ dye; $1 \mathrm{~g} \cdot \mathrm{L}^{-1}$ $\mathrm{Z}-\mathrm{Ag}_{\text {red. }}$

$\mathrm{pH}$ changes can influence the adsorption of the dye molecules onto the catalyst surface, an important step for the photocatalytic oxidation. It can be seen that the adsorption degree increased with $\mathrm{pH}$ shifting from acidic to alkaline medium, and a maximum degree is reached at $\mathrm{pH} 11(\sim 53 \%)$. This phenomenon is given by the dye nature and the catalyst surface charge. $\mathrm{MB}$ is a cationic dye and the catalyst surface charge shifts to more negative value with $\mathrm{pH}$ increasing, and the electrostatic attraction between dye molecule and catalytic surface is favored. Taking into consideration that the heterocatalytic oxidation mechanism involves the electron-hole pair generation, the alkaline medium should favors the photocatalytic oxidation, the aspect proved by its $\mathrm{pH}$ dependence. Also, the alkaline medium provides a larger concentration of hidrolxil ions available to generate $\mathrm{HO}^{\circ}$ radicals. Because the photocatalysis contribution in the global efficiency was almost the same at both $\mathrm{pH}$ values of 9 and 11 (about 23\% degradation; $25 \%$ decoloration at $180 \mathrm{~min}$ irradiation time), the further studies were carried out at $\mathrm{pH} 9$.

\subsubsection{Effect of catalyst dose}

In order to determine the optimum catalyst loading, the degradation of MB dye was investigated using different catalyst concentrations in the range of 0.25 $1.5 \mathrm{~g} \cdot \mathrm{L}^{-1}$. The results are presented in fig. 6 , and it can be observed that increasing the catalyst dose from 0.25 to $1.5 \mathrm{~g} \cdot \mathrm{L}^{-1}$ lead to increasing the dye discoloration efficiency from 22.3 to $83.9 \%$. This may be attributed to the enhanced generation of $\mathrm{HO}^{\circ}$ from the photocatalyst surface based on increasing the photocatalyst amount in the reaction solution. A similar behavior is noticed in the case of degradation efficiency, where the efficiency increases with the catalyst dose increasing up to $1.5 \mathrm{~g} \cdot \mathrm{L}^{-1}$. 

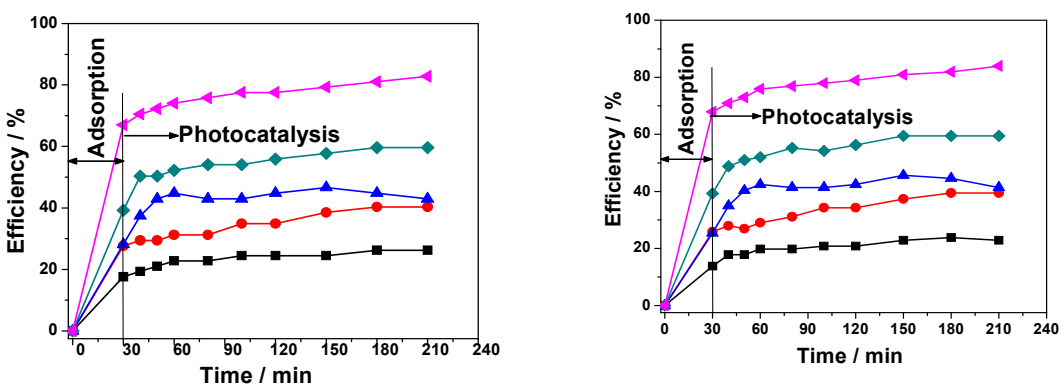

(a)

$-0.25 \mathrm{~g} \cdot \mathrm{L}^{-1} ; \bullet-0.5 \mathrm{~g} \cdot \mathrm{L}^{-1} ; \Delta-0.75 \mathrm{~g} \cdot \mathrm{L}^{-1} ; \triangleleft-1 \mathrm{~g} \cdot \mathrm{L}^{-1} ; \triangleleft^{-1.5 \mathrm{~g} \cdot \mathrm{L}^{-1}}$

Figure 6: Influence of dose on degradation (a) and discoloration (b) efficiency under VIS irradiation. Conditions: $50 \mathrm{mg} \cdot \mathrm{L}^{-1} \mathrm{MB}$ dye; $\mathrm{pH}=5.4$.

Based on the process efficiency evolution at the doses of 1.0 and $1.5 \mathrm{~g} \cdot \mathrm{L}^{-1}$, it can be noticed that even if the adsorption degree is significantly improved at $1.5 \mathrm{~g} \cdot \mathrm{L}^{-1}$ catalyst in comparison with $1.0 \mathrm{~g} \cdot \mathrm{L}^{-1}$, nevertheless the similar photocatalysis contribution was achieved for both doses, and $1.0 \mathrm{~g} \cdot \mathrm{L}^{-1}$ is selected as optimum dose.

\subsubsection{Effect of the initial dye concentrations}

The photodegradation efficiency depends on the initial dye concentration based on two main aspects.
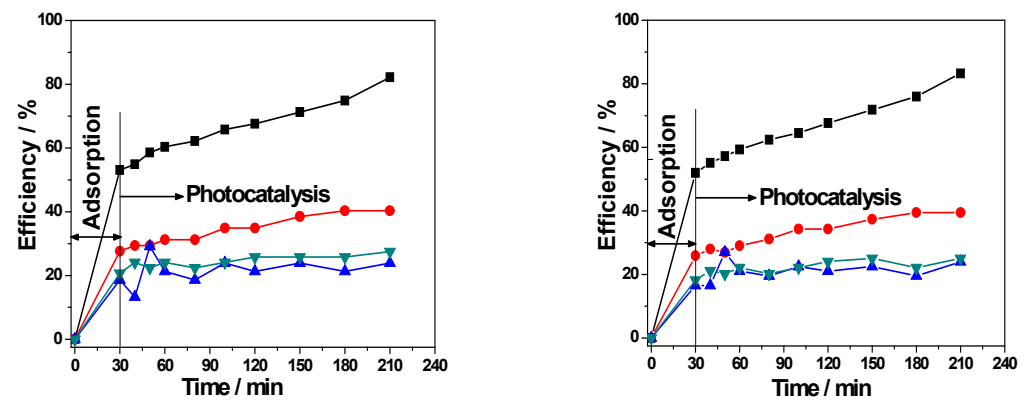

(a)

- $-20 \mathrm{mg} \cdot \mathrm{L}^{-1} ; \bullet-50 \mathrm{mg} \cdot \mathrm{L}^{-1} ; \mathbf{\Lambda}-70 \mathrm{mg} \cdot \mathrm{L}^{-1} ; \nabla-100 \mathrm{mg} \cdot \mathrm{L}^{-1}$

Figure 7: Influence of initial dye concentration on degradation (a) and discoloration (b) efficiency under VIS irradiation. Conditions: $1 \mathrm{~g}$. $\mathrm{L}^{-1} \mathrm{Z}-\mathrm{Ag}_{\text {red }} ; \mathrm{pH}=5.4$; reaction temperature- $20^{\circ} \mathrm{C}$. 
The amount of dye adsorbed on the catalytic surface increases with the dye concentration in relation with the available surface, which enhances the catalytic efficiency of the photocatalyst. On the other hand, higher concentration of the dye affects negatively the VIS light penetrability in the dye solution.

The influence of various initial dye concentrations on the photocatalytic discoloration and degradation has been investigated in the concentration range of 25-100 $\mathrm{mg} \cdot \mathrm{L}^{-1} \mathrm{MB}$ dye. The results show that the degradation/discoloration process efficiency decreased with initial dye increasing.

\section{Conclusion}

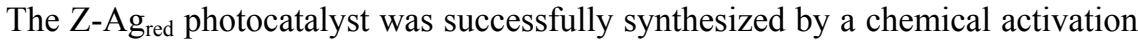
through ion exchange followed by a silver reduction with sodium boron hydride. The slight variations in the relative intensities of the clinoptilolite peaks found in the XRD pattern of Z-Ag, could be associated mainly with differences in the nature, amount and position of the extra-framework species in clinoptilolite channels. The presence of metallic Ag onto zeolite was proved by XRD and also, confirmed by EDX analysis. The DRUV-VIS spectra indicated that Z-Agred exhibited the large absorption bands significantly shifted to the visible range. Silver location into clinoptilolite network, positioned rather at the external zeolite surface was found from FTIR results. The photocatalytic activity of the $\mathrm{Z}-\mathrm{Ag}_{\text {red }}$ photocatalyst under VIS irradiation was proved for the degradation of MB dye solution. The solution $\mathrm{pH}$ value of 9 and the photocatalyst dose of $1 \mathrm{~g} \cdot \mathrm{L}^{-1}$ were established as optimal conditions for photocatalysis application in the degradation of RY 125 dye solution. The photocatalyst exhibited a good performance for discoloration and degradation processes especially at low concentrations, showing a real potential for practical photodegradation application under solar irradiation.

\section{Acknowledgements}

This work was supported by the strategic grant POSDRU 2009 project ID 50783 and ID 77265 of the Ministry of Labour, Family and Social Protection, Romania, co-financed by the European Social Fund - Investing in People, and partially from PN-II-ID-PCE-165/2011.

\section{References}

[1] Gaoa, B., Liua, B., Chena, T., and Yuea, Q., Effect of aging period on the characteristics and coagulation behavior of polyferric chloride and polyferric chloride-polyamine composite coagulant for synthetic dying wastewater treatment. Journal of Hazardous Materials, 187(1-3), pp. 413420, 2011.

[2] Qiu, Qiu, M., Qian, C., Xu, J., Wu, J. and Wang, G., Studies on the adsorption of dyes into clinoptilolite. Desalination, 243, pp. 286-292, 2009. 
[3] El-Desoky, H. S., Ghoneim, M. M., and Zidan, N. M. Decolorization and degradation of Ponceau $S$ azo-dye in aqueous solutions by the electrochemical advanced Fenton oxidation. Desalination, 264, pp. 143$150,2010$.

[4] Riga, A., Soutsas, K., Ntampegliotis, K., Karayannis and V., Papapolymerou G G., Effect of system parameters and of inorganic salts on the decolorization and degradation of Procion H-exl dyes. Comparison of $\mathrm{H}_{2} \mathrm{O}_{2} / \mathrm{UV}$, UV/Fenton, $\mathrm{TiO}_{2} / \mathrm{UV}$ and $\mathrm{TiO}_{2} / \mathrm{UV} / \mathrm{H}_{2} \mathrm{O}_{2}$ processes. Desalination, 211, pp. 72-86, 2007.

[5] Gurin V.S., Petranovskii V.P., Hernandez M.-A., Bogdanchikova N. and Alexeenko A.A., Silver and copper clusters and small particles, stabilized within nanoporous silicate-based materials. Materials Science and Engineering, A 391, pp. 71-76, 2005.

[6] Patterson H.H., Gomez R.S., Lu H. and Yson R.L., Nanoclusters of silver doped in zeolites as photocatalysts. Catalysis Today 120, pp. 168-173, 2007.

[7] Çağlar Duvarci Ö., Akdeniz Y., Özmihçi F., Ülkü S., Balköse D. and Çiftçioğlu M., Thermal behaviour of a zeolitic tuff. Ceramics International 33(5) pp. 795-801,2007.

[8] Concepción-Rosabal B., Rodríguez- Fuentes G., Bogdanchikova N., Bosch Bosch P. and Lara V.H., Comparative study on natural and synthetic Clinoptilolites containing silver in different states. Microporous and Mesoporous Materials, 86, pp. 249-255, 2005.

[9] Bogdanchikova N., Concepción-Rosabal B., Petranovskii V., Avalos-Borja M. and Rodríguez- Fuentes G., Different silver states stabilized in natural clinoptilolite. Proc. of the $13^{\text {th }}$ International Zeolite and Mesoporous Materials at the Dawn of the $21^{\text {st }}$ Century, eds. A.,Galarneau, F.,Di Renzo F.,Fajula \& Vedrine, Microporous ans Mesoporous Materials: France, 0-P15 Poster, 2001.

[10] Zhao D., Zhou J. and Liu N., Preparation and characterization of Mingguang palygorskite supported with silver and copper for antibacterial behavior. Applied Clay Science, 33, pp. 161-170, 2006.

[11] Rivera-Garza M., Olguín M. T., García-Sosa I., Alcántara D., and Rodríguez- Fuentes G., Silver supported on natural Mexican zeolite as an antibacterial material, Microporous and Mesoporous Materials, 39, pp. 431-444, 2000.

[12] C. Ratiu, C. Lazau, P. Sfirloaga, C. Orha, D. Sonea, S. Novaconi, F. Manea and G. Burtica, I. Grozescu, Decontaminate effect of the functionalized materials with undoped and doped $(\mathrm{Ag}) \mathrm{TiO}_{2}$ nanocrystals, Environmental Enginnering and Managemen Journal, 8(2), pp. 237, 2009. 